\title{
A REPRESENTAÇÃO DA VIOLÊNCIA CONTRA A MULHER NO CONTO EL SOLITARIO, DE HORACIO QUIROGA
}

\author{
THE REPRESENTATION OF VIOLENCE AGAINST WOMAN IN THE TALE \\ EL SOLITARIO, BY HORACIO QUIROGA
}

\author{
Marcela da Fonseca Ferreira ${ }^{1}$ \\ Felipe dos Santos Matias ${ }^{2}$
}

\begin{abstract}
Resumo: O presente artigo discute a questão da violência contra a mulher a partir do conto El solitario (1917), de Horacio Quiroga (1878-1937). A produção literária selecionada como corpus possibilita analisar a configuração relacionada aos papéis sociais atribuídos à mulher pela doxa patriarcal ocidental no período histórico referente ao início do XX. O referido texto do escritor uruguaio representa, por meio da relação entre o casal de personagens Kassim e María, a violência moral, psicológica e física perpetrada contra o gênero feminino. Como fundamentação teórico-crítica, utilizam-se as reflexões de Pierre Bourdieu, Jane Flax, Eduardo de Assis Duarte, Rita Terezinha Schmidt, Joan Scott, Lúcia Osana Zolin, Carlos Magno Gomes, dentre outros.
\end{abstract}

Palavras-chave: Quiroga; Violência; Mulher; El solitario.

\begin{abstract}
This article discusses the issue of violence against woman based on the short story El solitario (1917), by Horacio Quiroga (1878-1937). The literary production selected as a corpus makes it possible to analyze the configuration related to the social roles attributed to woman by the western patriarchal doxa in the historical period referring to the beginning of the XX. The referred text of the Uruguayan writer represents, through the relationship between the couple of characters Kassim and María, the moral, psychological and physical violence perpetrated against the female gender. As a theoretical-critical foundation, the reflections of Pierre Bourdieu, Jane Flax, Eduardo de Assis Duarte, Rita Terezinha Schmidt, Joan Scott, Lúcia Osana Zolin, Carlos Magno Gomes, among others, are used.
\end{abstract}

Keywords: Quiroga; Violence; Woman; El solitario.

\footnotetext{
1 Mestre em Literatura Comparada pela Universidade Federal da Integração Latino-Americana - UNILA. E-mail: marfonsecaf@hotmail.com

2 Professor da Universidade Federal da Integração Latino-Americana - UNILA. E-mail: felipe.matias@unila.edu.br
} 
Para Bourdieu (2002), as relações sociais são entremeadas pela dominação masculina e pela submissão feminina. Isso ocorre por meio da violência de gênero ${ }^{3}$, que, às vezes, é imperceptível, subjetiva, simbólica, podendo estar relacionada às estruturas de pensamento mais profundas, as quais sempre foram tratadas como "naturais", ou seja, como se fizessem parte da natureza humana. No entanto, Bourdieu (2002) afirma que tais estruturas têm uma origem, um intuito socioideológico, e a dominação masculina pode ser compreendida a partir disso. Dessa forma, o referido autor compreende que a violência simbólica se constrói de forma despercebida, conforme ilustra o fragmento a seguir:

Sempre vi na dominação masculina, e no modo como é imposta e vivenciada, o exemplo por excelência dessa submissão paradoxal, resultante daquilo que eu chamo de violência simbólica, violência suave, insensível, invisível a suas próprias vítimas que se exerce essencialmente pelas vias puramente simbólicas da comunicação e do conhecimento, ou, mais precisamente, do desconhecimento, do reconhecimento, ou em última instância, do sentimento (BOURDIEU, 2002, p. 5).

Outrossim, Bourdieu (2002) enfatiza que a violência simbólica aparenta-se como normal e parece estar na "ordem das coisas" por estar dentro de nossas categorias de entendimento, ou seja, da forma em que se compreende o mundo. Ela se exerce através das palavras e pensamentos e se funda na construção contínua de crenças que faz com que o sujeito se posicione na sociedade de acordo com os critérios e padrões do discurso dominante. Nesse sentido, a violência simbólica legitima outras formas de violência, como a física, por exemplo.

Bourdieu (2002) menciona que as formas de relação social perpetuadas pelo sistema patriarcal são estruturadas pela lógica da dominação, exercida em nome de um princípio simbólico, de um estilo de vida (ou maneira de pensar, de falar, de agir) e, mais geralmente, de uma propriedade distintiva, emblema ou estigma, dos quais o mais eficiente simbolicamente é a propriedade corporal. Para Bourdieu,

o mundo social constrói o corpo como realidade sexuada e como depositário de princípios de visão e de divisão sexualizantes. Esse programa social de percepção incorporada aplica-se a todas as coisas do mundo e, antes de tudo, do próprio corpo, em sua realidade biológica: é ele que constrói a diferença entre os sexos biológicos, conformando-a aos princípios de uma visão mítica do mundo, enraizada na relação arbitrária de dominação dos homens sobre as mulheres, ela mesma inscrita, com a divisão do trabalho, na realidade da ordem social (BOURDIEU, 2002, 18-19, grifos do autor).

\footnotetext{
3 Esta expressão é utilizada aqui no sentido definido por Maria Amélia Teles e Mônica de Melo, para as quais a "violência de gênero" consiste em "uma relação de poder de dominação do homem e submissão da mulher. Demonstra que os papéis impostos às mulheres e aos homens, consolidados ao longo da história e reforçados pelo patriarcado e sua ideologia, induzem relações violentas entre os sexos e indica que a prática desse tipo de violência não é fruto da natureza, mas sim do processo de socialização das pessoas [...]. A violência de gênero pode ser entendida como violência contra a mulher" (TELES e MELO, 2003, p. 18).
} 
Segundo Jane Flax, "o mais importante avanço isolado na teoria feminista consiste em se ter problematizado a existência de relações de gênero" (FLAX, 1991, p. 226). Para a autora, vivemos num mundo em que o gênero é uma relação social constituinte e também uma relação de dominação. A existência de relações de gênero nos ajuda a ordenar e entender os fatos da existência humana, as relações simbólicas que vigoram na sociedade como um todo e que tendem sempre a justificar a dominação masculina. Nessa direção, Pierre Bourdieu diz que:

A ordem social funciona como uma imensa máquina simbólica que tende a ratificar a dominação masculina sobre a qual se alicerça: é a divisão social do trabalho, distribuição bastante estrita das atividades atribuídas a cada um dos dois sexos, de seu local, seu momento, seus instrumentos; é a estrutura do espaço, opondo o lugar de assembleia ou de mercado, reservado aos homens, e a casa, reservada às mulheres; ou, no interior desta, entre a parte masculina, com o salão, e a parte feminina, com o estábulo, a água e os vegetais; é a estrutura do tempo, a jornada, o ano agrário, ou o ciclo de vida, com momentos de ruptura, masculinos, e longos períodos de gestação, femininos (BORDIEU, 2002, p. 18).

Segundo Eduardo de Assis Duarte, no contexto da crítica feminista, a categoria "gênero" pode ser entendida como processo de construção do feminino e do masculino na órbita da sociedade e da cultura. Enquanto o termo "sexo" liga-se aos condicionantes biológicos, portanto a uma possível "natureza", o conceito de gênero:

apela ao constante trabalho de formulação e manutenção dos sentidos e - mais que isto - de papeis sociais ou performances, como postula Judith Butler (1990). A reflexão feminista aponta para os dois planos da hegemonia masculina: o das ideias e o das práticas sociais. Assim, da mesma forma como a metafísica ocidental construiu o edifício teórico da Verdade, da Essência, do Bem e do Belo absolutos e universais, mais tarde desconstruídos com o desvelamento do locus delimitado e específico a partir do qual aspiravam à eternidade; a sociedade patriarcal, fundada numa relação entre homem e mulher conflitiva e, mesmo, "agonística", como defende Pierre Bourdieu (1999), criou, ao longo dos séculos, formas inúmeras para a permanente naturalização da subalternidade feminina, com base na pretensa inferioridade inata do chamado "sexo frágil" (DUARTE, 2002, p. 16-17, grifos do autor).

A partir das ideias de Joan Scott, pode-se dizer que o termo "gênero" permite, inicialmente, enfatizar o caráter fundamentalmente social das distinções baseadas no sexo. Para a crítica feminista do início dos anos 90 do século XX, a palavra "gênero" indicava uma rejeição do determinismo biológico implícito no uso de termos como "sexo" ou "diferença sexual". Segundo Scott, 
o termo "gênero", também é utilizado para designar as relações sociais entre os sexos. Seu uso rejeita explicitamente explicações biológicas, como aquelas que encontram um denominador comum, para diversas formas de subordinação feminina, nos fatos de que as mulheres têm a capacidade para dar à luz e de que os homens têm uma força muscular superior. Em vez disso, o termo "gênero" torna-se uma forma de indicar "construções culturais" (SCOTT, 1995, p. 75).

Scott também pontua que o gênero é uma forma primária de dar significado às relações de poder, ou seja, é um campo primário no interior do qual, ou por meio do qual, o poder é articulado. De acordo com a autora, a categoria gênero não é o único campo, mas parece ter sido uma forma persistente e recorrente de possibilitar a significação do poder no Ocidente, nas tradições judaico-cristãs e islâmicas. Para Scott,

Estabelecidos como um conjunto objetivo de referências, os conceitos de gênero estruturam a percepção e a organização concreta e simbólica da vida social. $\mathrm{Na}$ medida em que essas referências estabelecem distribuições de poder (um controle ou um acesso diferencial aos recursos materiais e simbólicos), o gênero torna-se implicado na concepção e na construção do próprio poder (SCOTT, 1995, p. 88).

Segundo Lúcia Osana Zolin, "no âmbito da literatura e da crítica literária, a mulher vem figurando entre os temas abordados em encontros, simpósios e congressos, bem como se constituindo em motivo de inúmeros cursos, teses e trabalhos de pesquisa" (ZOLIN, 2009 , p. 217). De acordo com a autora, os estudos sobre obras literárias canônicas evidenciam sólidas relações entre sexo e poder, visto que as relações entre casais espelham as relações de poder na sociedade patriarcal, na qual o homem busca se sobrepor à figura da mulher e a representa de acordo com a visão da ordem social falocêntrica.

De acordo com Rita Terezinha Schmidt (2002), a questão do cânone tem centralizado o foco da crítica feminista. Para a pesquisadora, o poder de representatividade dos textos literários canônicos reside na continuidade de sua repetição sob determinadas condições históricas, isto é, aquelas que viabilizam certa homogeneidade no discurso crítico, um dos pilares da instituição literária. Segundo Schmidt,

uma das consequências direta dessa homogeneidade, que se poderia traduzir como o discurso gendrado da crítica, foi o não reconhecimento da autoridade textual da voz feminina. [...] Se hoje a crítica feminista questiona o estatuto das configurações canônicas [...] é porque entende que a matriz ideológica que informou seus processos de formação está intimamente imbricada com o funcionamento institucional e social de hegemonias [...] as quais produziram relações desiguais na produção e distribuição de poder cultural, processos de subjetivação que implicaram no apagamento, às vezes de forma violenta, simbólica e literalmente, de outras identidades (SCHMIDT, 2002, p. 37-38). 
Partindo da reflexão acerca da questão de gênero e da opressão ocasionada pelas diferentes formas de violência contra a mulher na sociedade ocidental, este estudo objetiva fazer uma leitura ${ }^{4}$ analítica do texto literário El solitario, de Horacio Quiroga ${ }^{5}$, publicado no ano de 1917, no livro Cuentos de amor de locura y de muerte ${ }^{6}$. O conto de Quiroga mostra a relação entre um casal. O marido, Kassim, é apresentado ao leitor como um joalheiro que trabalhava para grandes casas do ramo. Sua especialidade era a montagem de pedras preciosas, labor ao qual se dedicava com esmero, conforme ilustra o fragmento a seguir:

Kassim era un [...] joyero de profesión, bien que tuviera tienda establecida. Trabajaba para las grandes casas, siendo su especialidad el montaje de las piedras preciosas. Pocas manos como las suyas para los engarces delicados. Con más arranque y habilidad comercial, hubiera sido rico. Pero a los treinta y cinco años proseguía en su pieza, aderezada em taller bajo la ventana (QUIROGA, 2007, p. 25).

Segundo o narrador do conto, em terceira pessoa, Kassim tinha uma jovem e linda esposa, que se chamava María. No entanto, percebe-se no texto a insatisfação da personagem feminina, que reclama da falta de carinho e atenção do marido para com ela, pois o joalheiro só vivia para o seu trabalho, não demonstrando sensibilidade às necessidades materiais e emocionais de sua companheira matrimonial, não tendo muito diálogo e afeto com a esposa. O excerto abaixo evidencia isso:

\footnotetext{
4 Em concordância com Lúcia Osana Zolin, pode-se dizer que ler "um texto literário tomando como instrumentos os conceitos operatórios fornecidos pela crítica feminista [...] implica investigar o modo pelo qual tal texto está marcado pela diferença de gênero, num processo de desnudamento que visa despertar o senso crítico e promover mudanças de mentalidades, ou, por outro lado, divulgar posturas críticas por parte dos(as) escritores(as) em relação às convenções sociais que, historicamente, têm aprisionado a mulher e tolhido seus movimentos. [...] O objetivo desses debates, se os contemplarmos de modo amplo, é a transformação da condição de subjugada da mulher. Trata-se de tentar romper com os discursos sacralizados pela tradição, nos quais a mulher ocupa, à sua revelia, um lugar secundário em relação ao lugar ocupado pelo homem, marcado pela marginalidade, pela submissão e pela resignação. Tais discursos não só interferem no cotidiano feminino, mas também acabam por fundamentar os cânones críticos e teóricos tradicionais e masculinos que regem o saber sobre a literatura" (ZOLIN, 2009, p. 218).
}

5 De acordo com Guilherme Silva da Cruz e María Silvina Sosa Vota, “o uruguaio Horacio Quiroga (1879-1937) tornou-se um dos expoentes da literatura latino-americana, particularmente por seus contos, com uma produção originada no início do século XX. Sua obra ganhou ênfase póstuma, principalmente nas influências expostas por autores como Julio Cortázar (1914-1984). Tornou-se uma referência para o teatro, cinema e televisão. Dois anos após sua morte rodava a primeira das mais de cinquenta adaptações de suas narrativas para o formato audiovisual. [...] Entre os anos de 1894 e 1936, teve uma produção intensa de críticas literárias, resenhas, inúmeros poemas, 170 contos e 15 livros. Tendo uma vida com situações peculiares, envolvendo mortes e um certo obscurantismo" (CRUZ e VOTA, 2017, p. 76).

6 Segundo Wellington Fioruci, na obra "Cuentos de amor de locura y de muerte, publicada em 1917, pode-se ver o trabalho apurado do escritor com a técnica narrativa, empregando com argúcia recursos estilísticos que fortalecem desde o início a tensão, denunciando a angústia existencial e problemas de ordem social. [...] O grande tema dos contos de Quiroga é, sem dúvida, a tragédia humana, a angústia da existência, o inevitável embate entre o ser e o outro, mutatis mutandis entre o sujeito e a sociedade. [...] Para tanto, sua escritura investe no envolvimento do leitor com a ordem sempre (in)tensa no desenvolvimento da ação narrativa, manipulada com precisão desde o início da leitura" (FIORUCI, 2015, p. 98-99, grifos nossos). 
[Kassim] Era un hombre indeciso, irresoluto y callado. Las miradas de su mujer se detenían ahora con más pesada fijeza sobre aquella muda tranquilidad.

— ¡Y eres un hombre, tú! — murmuraba.

Kassim, sobre sus engarces, no cesaba de mover los dedos.

— No eres feliz conmigo, María - expresaba al rato.

- ¡Feliz! ¡Y tienes el valor de decirlo! ¿Quién puede ser feliz contigo? ¡Ni la última de las mujeres!... ¡Pobre diablo! — concluía con risa nerviosa, yéndose.

Kassim trabajaba esa noche hasta las tres de la mañana [...]

- ¡Todos, cualquier marido, el último, haría un sacrificio para halagar a su mujer! Y tú... y tú... ni un miserable vestido que ponerme tengo! (QUIROGA, 2007, p. 24).

Ao longo da narrativa do conto, percebe-se que apesar de trabalhar com a confecção de joias, Kassim não dá de presente a María nenhum dos adornos que fabrica, nem mesmo permite que a esposa experimente ou pegue emprestado algum dos objetos feitos por ele. Quando não encontra algum desses itens, Kassim logo pressupõe e acusa implicitamente María de ser a responsável, evidenciando a violência moral ${ }^{7}$ e psicológica ${ }^{8}$ contra a mulher, pois ele a trata com muita desconfiança, como se fosse uma ladra, o que explicita a falta de respeito com a esposa:

Una tarde, al guardar sus joyas, Kassim notó la falta de un prendedor — cinco mil pesos en dos solitários - Buscó en sus cajones de nuevo.

— ¿No has visto el prendedor, María? Lo dejé aqui.

7 De acordo com o site do Tribunal de Justiça do Distrito Federal e dos Territórios (TJDFT), a lei 11.340/2006, conhecida como Lei Maria da Penha, expressa que a violência moral praticada contra a mulher é "entendida como qualquer conduta que configure calúnia, difamação ou injúria" (TRIBUNAL DE JUSTIÇA DO DISTRITO FEDERAL E DOS TERRITÓRIOS, 2020, s/p).

8 No que concerne à violência psicológica contra a mulher, "especialistas apontam que, apesar de não deixar marcas físicas evidentes, a violência psicológica é também uma grave violação dos direitos humanos das mulheres, que produz reflexos diretos na sua saúde mental e física. Considerada pela Organização Mundial de Saúde (OMS) como a forma mais presente de agressão intrafamiliar à mulher, sua naturalização é apontada ainda como estímulo a uma espiral de violências. Pode preceder, inclusive, a mais extrema violência, o feminicídio, conforme apontam esses especialistas. O artigo $7^{\circ}$ da Lei $n^{\circ}$ 11.340 tipifica como violência psicológica qualquer conduta que cause dano emocional ou prejuízo à saúde psicológica e à autodeterminação da mulher; diminuição, prejuízo ou perturbação ao seu pleno desenvolvimento; que tenha o objetivo de degradá-la ou controlar suas ações, comportamentos, crenças e decisões mediante ameaça, constrangimento, humilhação, manipulação, isolamento, vigilância constante, perseguição, insulto, chantagem, ridicularização, exploração, limitação do direito de ir e vir ou qualquer outro meio" (COMPROMISSO E ATITUDE, 2020, s/p). 
—Sí, lo he visto.

—¿Dónde está? — se volvió extrañado.

—Aquí!

Su mujer, los ojos encendidos y la boca burlona, se erguía con el prendedor puesto.

—Te queda muy bien — dijo Kassim al rato —. Guardémoslo. [...]

Kassim se levantó y la guardó en su taller bajo llave. Al volver, su mujer estaba sentada en la cama.

— ¡Es decir, que temes que te la robe! ¡Que soy una ladrona! [...]

- ¡Ah! ¡Y a ti te lo confían! ¡A ti, a ti! ¡Y cuando tu mujer te pide un poco de halago, y quiere... me llamas ladrona a mí! ¡Infame! (QUIROGA, 2007, p. 25).

Na parte da metade para o final do conto, a personagem María expõe ao marido Kassim o seu descontentamento e revolta em relação ao relacionamento matrimonial que mantinham, evidenciando o arrependimento por ter se casado com um homem insensível e egoísta. Como resposta, Kassim adota a estratégia de dizer que a esposa está doente, dizendo coisas sem sentido, adotando uma conduta/artimanha, bastante difundida na sociedade patriarcal falocêntrica, de desqualificar/silenciar o discurso feminino, ato contrário à desejada liberdade de expressão social, o que configura claramente uma situação de violência ${ }^{9}$ simbólica contra a mulher:

— ¡Tú eres el ladrón, miserable! ¡Me has robado mi vida, ladrón, ladrón! Y creías que no me iba a desquitar... [...] ¡Ajá! Mírame... no se te había ocurrido nunca, ¿eh? ¡Ah! — y se llevó las dos manos a la garganta ahogada. [...]

Kassim la ayudó a levantarse, lívido.

— Estás enferma, María. Después hablaremos... acuéstate. [...]

Kassim sonrió de nuevo, tocándole con torpe cariño la mano.

\footnotetext{
9 Em conformidade com as ideias de Carlos Magno Gomes, pode-se considerar que "a violência também pode ser vista como um ato de desespero de homens que não aceitam nem o sucesso social, nem o direito à liberdade das mulheres. Dessa forma, destacamos o fato de a flexibilidade da identidade de gênero não ser reconhecida pelo agressor masculino. Daí a importância dos estudos feministas e de gênero para uma avaliação das representações simbólicas dessa violência na ficção [...] no campo social, tem-se a tradição cultural da dominação masculina" (GOMES, 2013, p. 4).
} 
— ¡Loca! Te digo que no me acuerdo de nada.

Y se levantó a proseguir su tarea. Su mujer, con la cara entre las manos, lo siguió con la vista.

— Y no me dice más que eso... - murmuró. Y con una honda náusea por aquello pegajoso, fofo e inerte que era su marido, se fue a su cuarto (QUIROGA, 2007, p. 25).

No fim da narrativa, temos a descrição de uma cena de violência física e feminicídio. Karim, após o desabafo de María, resolve fria e covardemente assassiná-la, fincando um alfinete no coração de sua esposa, quando ela estava dormindo. A crueldade perpetrada pelo personagem é o ato final de uma relação pautada na dominação masculina, na desigualdade de gênero e na violência contra a mulher. Quando María expressa o seu descontentamento a respeito do relacionamento com o marido, refutando o papel de mulher submissa preconizado pelo machismo estrutural da cultura do patriarcado, Karim, como vingança, decide matá-la, conforme se observa no seguinte fragmento:

A las dos de la mañana Kassim pudo dar por terminada su tarea; el brillante resplandecía, firme y varonil en su engarce. Con paso silencioso fue al dormitorio y encendió la veladora. María dormía de espaldas, en la blancura helada de su camisón y de la sábana.

Fue al taller y volvió de nuevo. Contempló un rato el seno casi descubierto, y con una descolorida sonrisa apartó un poco más el camisón desprendido.

Su mujer no lo sintió.

No había mucha luz. El rostro de Kassim adquirió de pronto una dura inmovilidad, y suspendiendo un instante la joya a flor del seno desnudo, hundió, firme y perpendicular como un clavo, el alfiler entero en el corazón de su mujer.

Hubo una brusca apertura de ojos, seguida de una lenta caída de párpados. Los dedos se arquearon, y nada más.

La joya, sacudida por la convulsión del ganglio herido, tembló un instante desequilibrada. Kassim esperó un momento; y cuando el solitario quedó por fin perfectamente inmóvil, pudo entonces retirarse, cerrando tras de sí la puerta sin hacer ruído (QUIROGA, 2007, p. 26).

Apesar da leitura feita até aqui no que concerne às formas de violência contra a mulher constituídas no conto El solitario, há que se fazer uma ressalva em relação à conduta do narrador, em terceira pessoa, no tex to de Quiroga, visto que o mesmo se coloca, ao longo da 
narrativa, nitidamente a favor de Kassim, tentando passar para o leitor a ideia de que María era uma mulher fútil e interesseira, que não reconhecia o esforço que o marido dedicava ao trabalho dele. Representando as relações de poder ${ }^{10}$ alicerçadas no imaginário de uma sociedade machista e falocêntrica relativa ao início do século XX (imaginário este que, infelizmente, ainda perdura em nosso tempo contemporâneo), o narrador trata como natural o fato de o esposo não dedicar muita atenção à cônjuge, disseminando a ideia de que o homem deveria se preocupar com o seu ofício e que a mulher tinha que ser compreensiva e submissa em relação ao marido, não podendo expor suas ideias e nem fazer críticas em relação ao comportamento do parceiro matrimonial. Os excertos que se seguem evidenciam isso:

La joven [María], de origen callejero, había aspirado con su hermosura a un más alto enlace. Esperó hasta los veinte años, provocando a los hombres y a sus vecinas con su cuerpo. Temerosa al fin, aceptó nerviosamente a Kassim.

No más sueños de lujo, sin embargo. Su marido, hábil artista aún, carecía completamente de carácter para hacer una fortuna. Por lo cual, mientras el joyero trabajaba doblado sobre sus pinzas, ella, de codos, sostenía sobre su marido una lenta y pesada mirada, para arrancarse luego bruscamente y seguir con la vista tras los vidrios al transeúnte de posición que podía haber sido su marido. [...]

— Hago, sin embargo, cuanto puedo por ti — decía él al fin, tristemente.

Los sollozos subían con esto, y el joyero se reinstalaba lentamente en su banco.

Estas cosas se repitieron, tanto que Kassim no se levantaba ya a consolarla. ¡Consolarla! ¿de qué? Lo cual no obstaba para que Kassim prolongara más sus veladas a fin de un mayor suplemento. [...]

Cuando se franquea cierto límite de respeto al varón, la mujer puede llegar a decir a su marido cosas increíbles.

La mujer de Kassim franqueó ese límite con una pasión igual por lo menos a la que sentía por los brillantes. [...]

A compás del montaje del solitario, Kassim recibió sobre su espalda trabajadora cuanto ardía de rencor y cocotaje frustrado en su mujer (QUIROGA, 2007, p. 25-26).

10 Nessa direção, Lúcia Osana Zolin diz que "estudos acerca de textos literários canônicos mostram inquestionáveis correspondências entre sexo e poder: as relações de poder entre casais espelham as relações de poder entre homem e mulher na sociedade em geral; a esfera privada acaba sendo uma extensão da esfera pública. Ambas são construídas sobre os alicerces da política, baseados nas relações de poder" (ZOLIN, 2009, p. 217-218). 
No desfecho da narrativa, tem-se a impressão de que o narrador trata o feminicídio de María como se fosse algo justificado moralmente perante o patriarcalismo, o qual legitima tal violência como crime de honra ${ }^{11}$. Analisando-se a ótica do narrador no conto, observa-se que toda a narrativa caminha na direção de culpabilizar a vítima, dando a entender que o ato extremo do assassinato foi provocado por a esposa não ter "respeitado" e "obedecido" o marido. Seria possível inferir, então, que o próprio foco narrativo do texto literário em questão é uma forma de violência de gênero, na medida em que contribui para se disseminar e naturalizar os diferentes tipos de violência contra a mulher.

Lamentavelmente, percebe-se que a violência contra a mulher analisada neste conto, escrito no início do século XX, é um fenômeno que persiste e se encontra presente na contemporaneidade. Mesmo com o crescimento do movimento feminista e com alguns avanços sociais, como acesso ao voto, ao ensino, ao trabalho - negados por séculos -, como também o reconhecimento da Lei Maria da Penha, em 2006, da Lei do Feminicídio, em 2015 e, por fim, a Lei da Importunação Sexual, em 2018, as mulheres permanecem vítimas de violências permeadas pela desigualdade de gênero. Fica evidente, portanto, o descompasso entre o notável arcabouço legal e a frágil implementação de políticas públicas voltadas a efetivamente coibir e punir esse tipo de violência.

Assim, observa-se que a proteção estatal, idealmente embasada na Constituição, demonstra-se incapaz de proteger e amparar as vítimas, pois a sociedade ainda mantém conceitos patriarcais e misóginos, por meio, por exemplo, da violência simbólica contra a mulher - uma violência "invisível”, sutil e imperceptível -, a qual é fundamentada na permanência dos valores sociais e é exercida por meios genuinamente simbólicos de conhecimento e comunicação. Por fim, ressalta-se que, enquanto alguns aspectos da práxis social forem considerados inquestionáveis e sua existência for compreendida como "natural" e não como construção sociohistórica e cultural, a violência contra as mulheres persistirá.

\footnotetext{
11 De acordo com Carlos Magno Gomes, "a partir do contexto de luta feminista, a ficção tenta ir além da questão moral da violência doméstica e passa a questionar o fato de essa violência estar relacionada à defesa da honra masculina. Nesse sentido, diversas pesquisas apontam que o controle do poder e a defesa da honra estão entre os motivos da violência contra a mulher, pois 'em nome do controle, do poder e dos ciúmes, os atos tendem a ser de violência cotidiana e crônica, física, psíquica. Podem e desencadeiam em morte’ (MACHADO, 2010, p. 57). Fora de controle, o homem elimina sua companheira por motivos torpes. Esse ser vingativo não cabe mais nos espaços contemporâneos de constantes mudanças dos paradigmas familiares" (GOMES, 2013, p. 5).
} 


\section{REFERÊNCIAS}

BOURDIEU, Pierre. A dominação masculina. Trad. de Maria Helena Kühner. 2. ed. Rio de Janeiro: Bertrand Brasil, 2002.

CRUZ, Guilherme Silva da; VOTA, María Silvina Sosa. Horacio Quiroga e Los Desterrados: o ser e estar na fronteira. Cadernos do IL, Porto Alegre, n. 53, p. 75-88, jan. de 2017. Disponível em: https:// seer.ufrgs.br/cadernosdoil/article/view/67361. Acesso em: 20 de abril de 2020.

DUARTE, Eduardo de Assis. Feminismo e desconstrução: anotações para um possível percurso. In: DUARTE, Constância Lima; DUARTE, Eduardo de Assis; BEZERRA, Kátia da Costa (orgs.). Gênero e representação: teoria, história e crítica. Belo Horizonte: Editora UFMG, 2002, p. 13-31.

FIORUCI, Wellington. As palavras e o mundo na prosa de Quiroga. Revista Língua \& Literatura, v. 17, n. 28, p. 98-108, ago. de 2015. Disponível em: http://revistas.fw.uri.br/index.php/ revistalinguaeliteratura/article/view/1701. Acesso em: 20 de abril de 2020.

FLAX, Jane. Pós-modernismo e relações de gênero na teoria feminista. In: HOLANDA, Heloísa Buarque de (org.). Pós-modernismo e política. Rio de Janeiro: Rocco, 1991, p. 217-250.

GOMES, Carlos Magno. Marcas da violência contra a mulher na literatura. Diadorim, Rio de Janeiro, v. 13, p. 01-11, jul. de 2013. Disponível em: https://revistas.ufrj.br/index.php/diadorim/article/ view/3981. Acesso em: 21 de abril de 2020.

QUIROGA, Horacio. El solitario. In: Cuentos de amor, de locura y de muerte. Buenos Aires: Agebe, 2007.

SCHMIDT, Rita Terezinha. Escrevendo gênero, reescrevendo a nação: da teoria, da resistência, da brasilidade. In: DUARTE, Constância Lima; DUARTE, Eduardo de Assis; BEZERRA, Kátia da Costa (orgs.). Gênero e representação: teoria, história e crítica. Belo Horizonte: Editora UFMG, 2002, p. 32-44.

SCOTT, Joan. Gênero: uma categoria útil de análise histórica. Educação \& Realidade, v. 20, n. 2, p. 7179, jul./dez. de 1995.

SOBRE a violência moral e psicológica contra mulheres. Compromisso e Atitude, 2020. Disponível em: http://www.compromissoeatitude.org.br/violencia-moral-e-psicologica/. Acesso em: 22 de abril de 2020.

TELES, Maria Amélia de Almeida; MELO, Mônica de. O que é a violência contra a mulher. São Paulo: Brasiliense, 2003.

VIOLÊNCIA Moral. Tribunal de Justiça do Distrito Federal e dos Territórios, 2020. Disponível em: https://www.tjdft.jus.br/institucional/imprensa/campanhas-e-produtos/direito-facil/edicao-semanal/ 
violencia-moral. Acesso em: 22 de abril de 2020.

ZOLIN, Lúcia Osana. Crítica feminista. In: BONNICI, Thomas; ZOLIN, Lúcia Osana (orgs.). Teoria literária: abordagens históricas e tendências contemporâneas. 3. ed. Maringá: Eduem, 2009, p. 217-242. 